\title{
Arterial spin labeling assessment of myometrial perfusion changes in patients with uterine fibroid and its impact on fertility
}

Magda Mohammed Shawky Shady', Ahmed Fathy El-said Gibreel ${ }^{2}$, Dina Rashed Mohammed Rashed ${ }^{1}$ and Nehal Tharwat ${ }^{1 *}$ (iD

\begin{abstract}
Background: Fibroids are the most common uterine tumor in the reproductive age group. These tumors although benign, their relation to infertility is still controversial. The purpose of this study is to assess the fibroid impact on fertility using arterial spin labeling (ASL) technique.

Results: This prospective study included 40 cases (30 female patients having uterine fibroid and 10 age- and sexmatched control cases). The 30 patients were divided according to their fertility into 2 subgroups: fertile $(n=15)$ and infertile $(n=15)$. All cases underwent pelvic magnetic resonance imaging (MRI) examination with ASL technique. The perfusion values were measured in the uterine walls, fibroids, and in the gluteus maximus muscle as control. ASL demonstrated non-significant difference in the perfusion between anterior and posterior uterine walls in the control cases and revealed significant difference in the perfusion between fibroid positive and fibroid negative uterine walls in patients with uterine fibroid ( $p$ value $<0.04$ ). Perfusion values of the fertile and infertile subgroups showed no statistically significant difference.

Conclusion: Arterial spin labeling is an evolving technique that can be used to evaluate the myometrial perfusion changes in patients with uterine fibroid without using contrast media. Uterine fibroids were associated with decreased perfusion but with no statistically significant impact on fertility.
\end{abstract}

Keywords: Arterial spin labeling, Perfusion, Fibroid, Fertile, Infertile

\section{Background}

Fibroids are the most common uterine tumor in the reproductive age group affecting $20-50 \%$ of women at this age. These tumors although benign, their relation to infertility is still controversial and is always of great concern to the clinician as well as the patient $[1,2]$.

They are often asymptomatic, but they can cause multiple symptoms such as abnormal uterine bleeding, feeling of pelvic pressure, urinary retention, or pain.

\footnotetext{
* Correspondence: nehaltharwat83@gmail.com

${ }^{1}$ Diagnostic Radiology Department, Faculty of Medicine, Mansoura University, Algomhoria Street, Mansoura City 35516, Egypt

Full list of author information is available at the end of the article
}

They may also be associated with reproductive problems such as subfertility, early pregnancy loss, and later pregnancy complications such as pain, preterm labor, malpresentations, increased need for caesarean section, and postpartum hemorrhage [3-5].

Uterine fibroids are classified according to their location into submucosal, intramural, or subserosal. Submucosal fibroids are the least common type, accounting for just $5 \%$ of all fibroids, but they are the most likely to be symptomatic since they project into the endometrial cavity. Intramural fibroids are the most common type, but they are usually asymptomatic; however, they may cause infertility due to compression of the fallopian 
tubes. Intramural and submucosal myomas that distort the endometrial cavity are associated with lower pregnancy, implantation, and delivery rates in women undergoing in vitro fertilization (IVF) [6, 7].

Although uterine fibroids are known to be benign tumors with reduced vascularization, recent work demonstrates that the vasculature of fibroids is grossly and microscopically abnormal. The presence of uterine fibroids usually results in distortion of the uterine arteries which supply both normal myometrium and the fibroids. It has been suggested that an inadequate blood supply caused by uterine fibroids may lead to decreasing fertility $[8,9]$.

Arterial spin labeling (ASL) is a particularly promising magnetic resonance imaging (MRI) perfusion methodology that uses electromagnetically labeled arterial blood water as endogenous tracer for evaluation of tissue blood flow and was firstly applied to the brain [10-13].

The use of ASL to evaluate blood flow in the pelvic organs has not been well established. This non-invasive technique might be useful to evaluate blood flow in the uterus to improve the outcome of infertility treatments. ASL technique can be used to examine blood flow in the uterine muscle layer in patients with uterine fibroids [14-16].

The purpose of this study is to assess the fibroid impact on fertility using ASL technique.

\section{Methods}

This prospective study was performed between September 2018 and September 2019 on convenience sample approved by institutional review board. Patients were referred from Gynecology and Obstetrics Department and outpatient clinic to MRI unit. This study included 40 cases (30 female patients having uterine fibroid with mean age $38.7 \pm 5.22$ and 10 sex- and age-matched normal healthy control cases not suffering from any systemic or gynecologic diseases with mean age $34.6 \pm 5.8)$. The 30 patients were grouped into two subgroups: fertile $(n=15)$ and infertile $(n=15)$. Approval of institutional board for the study and written informed consent from all participants were obtained.

\section{Inclusion criteria}

(1) Patients in child bearing period diagnosed to have uterine fibroid by previous ultrasound (US) and/or MRI examination. The patients were divided into two subgroups: fertile $(n=15)$ and infertile $(n=15)$.

(2) For the infertile subgroup: patients with either primary or secondary infertility with a duration more than 2 years and no apparent causes explaining infertility rather than fibroids (for example: normal basal hormonal profile, regular menstruation and normal ovulation as documented by either ultrasonography during late follicular-early luteal phase or by normal mid-luteal serum progesterone levels) confirmed by an expert gynecologist with 20 years' experience were included in the study.

\section{Exclusion criteria}

(1) Absolute contraindications to MRI scan (pacemaker, metallic orthopedic plates, etc.), relative contraindications (irritable patient, claustrophobia), uncooperative patients with excessive motion and bad general condition.

(2) For infertile subgroup: history of pelvic surgery, hydrosalpinx, any pelvic pathology including adenomyosis or ovarian cysts, or any general disease or medication that could potentially affect pelvic blood flow were excluded from study.

All cases were subjected to: full history-taking, clinical examination, and full laboratory investigation.

\section{MRI examination}

All patients underwent MRI examination by a 1.5 Tesla scanner (Ingenia Philips). Patients were imaged in the supine position, head first using pelvic phased-array coil. Head phones were used to reduce repetitive gradient noise. T1 WI $(\mathrm{TR}=500 \mathrm{~ms}$, $\mathrm{TE}=25 \mathrm{~ms}$, matrix $80 \times$ 80 , FOV $250 \times 170$, slice thickness $6 \mathrm{~mm}$ ) and T2 WI $(\mathrm{TR}=4000 \mathrm{~ms}, \mathrm{TE}=120 \mathrm{~ms}$, matrix $80 \times 80$, FOV 250 $\times 170$, slice thickness $6 \mathrm{~mm}$, gap $1 \mathrm{~mm}$ ) in axial, sagittal, and coronal planes were obtained.

\section{ASL data acquisition}

ASL perfusion imaging was performed with pseudocontinuous labeling technique (pCASL) and multiple time points acquired after the label pulse. Uterine perfusion measurements were acquired in an axial slice with cardiac torso coil using a flow-sensitive alternating inversion recovery (FAIR) single shot Turbo spin-echo acquisition scheme. Briefly, labeling pulse was positioned to cover bilateral common iliac arteries. From 1 to $3 \mathrm{~s}$ after labeling, signal intensities were measured in the uterus. Parameters used were TR/TE 3600/5.9 ms, echo train length 21 , matrix $128 \times 96$, FOV $230 \times 230 \mathrm{~mm}$, imaging tagging slice thickness $10 / 200 \mathrm{~mm}$. Imaging time for each inversion time was $90 \mathrm{~s}$. The slice which exhibited the maximum area of uterine fibroid was used.

\section{Determination of the optimal scanning time of ASL}

The ASL signals in the uterus were observed at $1 \mathrm{~s}$ after labeling, and increased until $1.5 \mathrm{~s}$, then attenuated. The optimal scanning time $1.5 \mathrm{~s}$ after labeling was set.

\section{ASL post-processing}

The DICOM images were transferred to workstation (extended MR Workspace 2.6.3.5, Philips medical systems). The post-processing of arterial spin-tagging data typically involves initially subtraction of alternating tag 
and control image pairs, motion correction, and generating ASL gray scale and colored map. A visual evaluation of the colored perfusion map calculated on the MR scanner using software provided.

Region of interests (ROIs) consisted of a 5-mm diameter circle were manually set as follows:

(1) In the control group: ROIs were set in the myometrium of the anterior wall and the posterior wall of the uterus and in the control muscle (iliopsoas or gluteus maximus).

(2) In patients with fibroid: the ROIs were set in the myometrium of the positive wall (containing the fibroid), in the myometrium of the negative wall (not containing the fibroid), in the fibroid itself avoiding areas of necrosis and in the control muscle (iliopsoas or gluteus maximus) (Fig. 1). In the presence of multiple fibroids, we consider the positive wall to be the wall having the largest fibroid.

The perfusion value and perfusion index (perfusion index $=$ perfusion value of the uterine wall-perfusion value of the control muscle) of each of the previously selected ROIs were obtained.

Perfusion values and indices were compared among the following different groups:

(1) Control group and patients with uterine fibroid.

(2) Fertile and infertile fibroid subgroups.

\section{Statistical analysis}

Data were tabulated, coded, and then analyzed using the computer program SPSS (Statistical Package for Social Science) version 23.0. Descriptive statistics were calculated in the form of mean \pm standard deviation (SD), median, interquartile range (IQR), and frequency (Number-percent). In the statistical comparison between the different groups, the significance of difference was tested

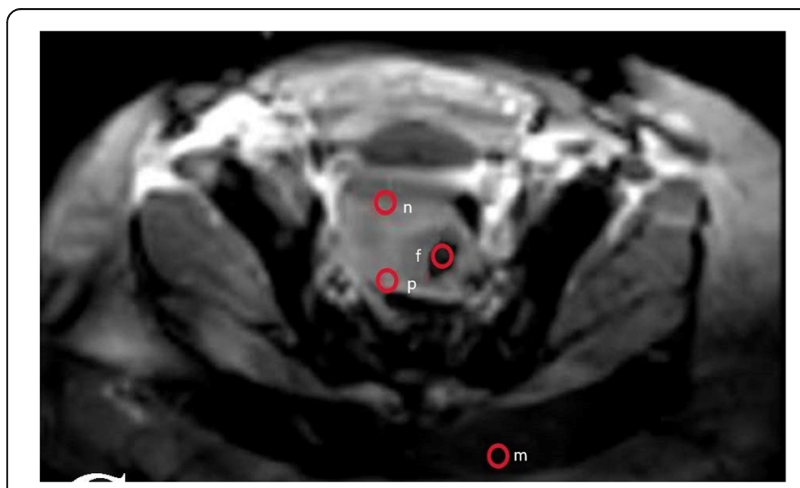

Fig. 1 ROI localization in fibroid patients, in this image the ROls were put in the myometrium of the posterior wall which possesses the fibroid (positive wall: $p$ ), in the anterior wall myometrium that does not possess the fibroid (negative wall: $n$ ), in the fibroid itself ( $f$ ), and in the gluteus maximus muscle (m) using the suitable test. Student's $t$ test (unpaired) was used to compare between mean of two different groups of numerical (parametric) data. Mann-Whitney test was used to compare between two different groups of numerical (non-parametric) data. One-way ANOVA test (analysis of variance) was used to compare between more than two different groups of numerical (parametric) data. Kruskal-Wallis test was used to compare between more than two different groups of numerical (non-parametric) data. Inter-group comparison of categorical data was performed by using Pearson's chi square test $\left(\chi^{2}\right.$ value). Spearman's correlation coefficient test was used to correlate different parameters. A $P$ value $<0.05$ was considered statistically significant.

\section{Results}

All types of fibroid were included in this study. In the fertile group, the intramural fibroid was the most common type and the submucous fibroid was the least common type. In the infertile group, the submucous type was the most common type while the subserous was the least common type with significant difference between the two groups ( $p$ value $=0.01^{*}$ ).

\section{MRI perfusion analysis with ASL}

In the control group, no statistically significant difference was detected as regards the perfusion indices between the anterior and posterior uterine walls ( $p$ value $=0.7$ ). The perfusion indices ranged in the anterior wall from 180 to 529 , median 331, while in the posterior wall ranged from 168 to 514, median 370 (Fig. 2).

On the other hand, in patients with uterine fibroid, the positive wall perfusion indices were significantly lower than the negative wall perfusion indices $(p$ value $=$ $\left.0.04^{*}\right)$, and this difference was similarly noted in both fertile and infertile subgroups (Figs. 3 and 4). Perfusion values and perfusion indices of the positive wall, negative wall, and control muscle perfusion are demonstrated in Tables 1 and 2.

No statistically significant difference was noted between the perfusion indices of the positive walls among the fertile and infertile subgroups ( $p$ value $=0.5$ ). Also, no statistically significant difference was noted between the perfusion indices of the negative walls among the fertile and infertile subgroups ( $p$ value $=0.37$ ) as shown in Table 3, denoting that the impairment of myometrial perfusion caused by the fibroid does not affect the fertility as a sole factor.

The fibroid perfusion indices ranged from 151 to 628 , median 395. The positive wall perfusion indices ranged from 162 to 598, median 420. Though the median value for the fibroid was lower than that of the positive wall, yet this difference was statistically non-significant $(p$ value $=0.94)$. 

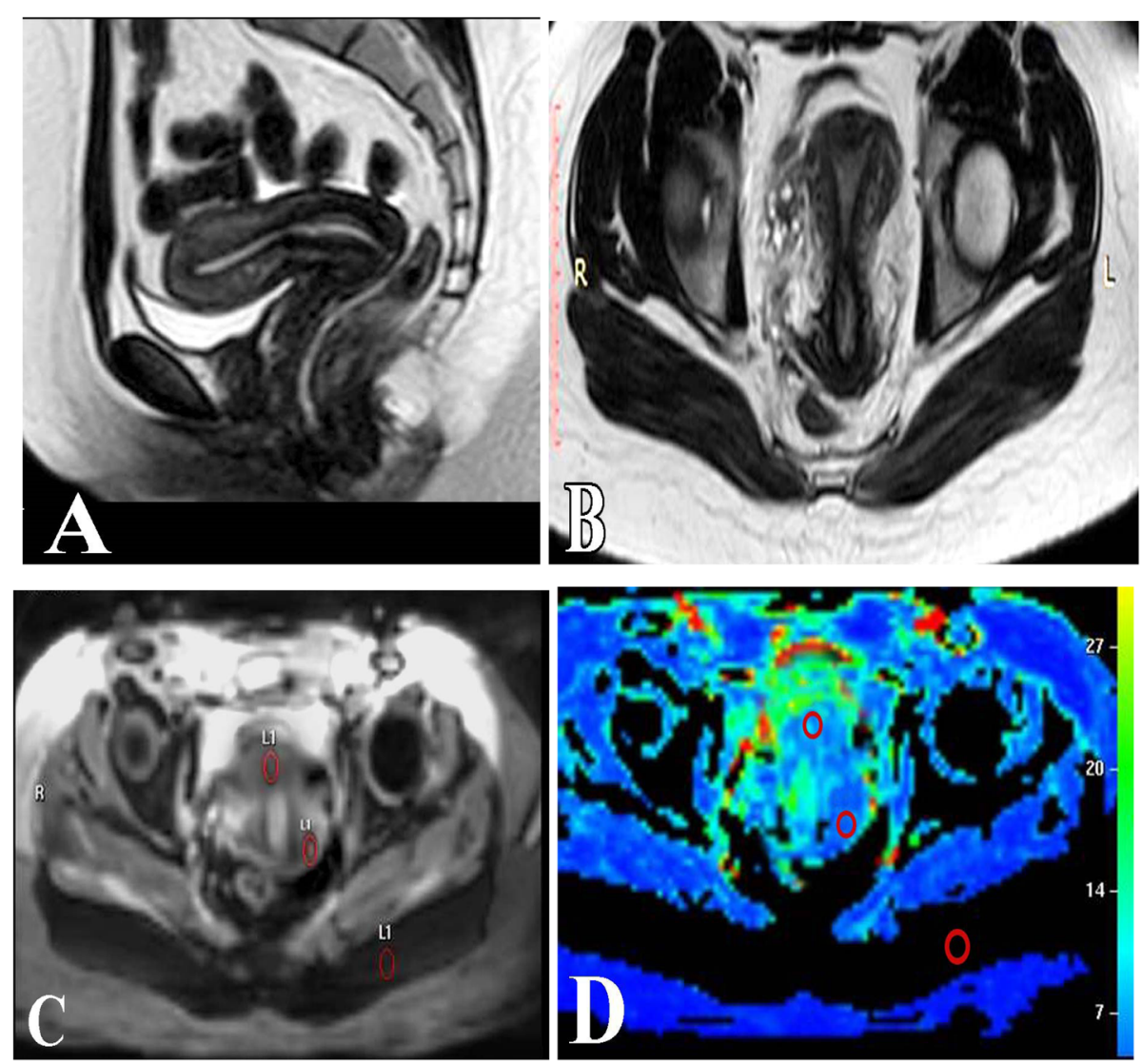

Fig. 2 Normal control female case aged 30 years old. a, b Sagittal and axial T2WI of the uterus. c ASL gray scale map with the ROls put at the anterior wall, posterior wall of the uterus, and in the gluteus muscle. $\mathbf{d}$ ASL color map with the ROls put at the anterior wall, posterior wall of the uterus, and in the gluteus muscle. In this case, the ASL perfusion in the anterior wall was 243 and in the posterior wall was 238

The negative wall perfusion indices ranged from 262 to 734, median 642, while the fibroid perfusion indices ranged from 151 to 628 , median 395. On comparing these values, we noticed lower perfusion indices of the fibroid than that of the negative uterine wall, yet this difference was statistically non-significant ( $p$ value $=0.06$ ).

\section{Discussion}

Uterine fibroids may have negative impact on fertility. The mechanisms by which myomas affect fertility are mainly attributed to anatomical causes as deformity of the uterine cavity, obstruction of the proximal fallopian tubes, altered tubo-ovarian anatomy, disordered uterine contractility, distortion of the endometrium and consequently of implantation, then vascular causes as impaired endometrial blood flow, endometrial inflammation, and abnormal secretion of vasoactive substances [2, 17-20].

In the uterus, adequate blood flow is important to maintain fertility. It has been suggested that an inadequate blood supply caused by uterine fibroids may lead to decreasing fertility, implantation failure, and gestation discontinuation. Therefore, a quantitative evaluation of blood flow in the uterus might be a good tool for infertility treatments [21].

The two most common methods for measuring perfusion with MRI are based on dynamic susceptibility contrast (DSC) and ASL [10, 14]. ASL perfusion technique uses electromagnetically labeled arterial blood water as endogenous tracer instead of externally injected tracer for evaluation of tissue blood flow. ASL is a particularly promising MRI methodology for basic research because it enables non-invasive quantitative tissue blood flow measurements without ionizing radiation exposure and administration of contrast materials $[11,22,23]$.

In this study, 40 cases underwent ASL examination to evaluate perfusion of myometrium by using the pseudocontinuous ASL technique. Pseudo-continuous ASL has the potential of combining the merits of pulsed ASL (PASL), including less hardware demand and higher tagging efficiency, and continuous ASL (CASL), which 

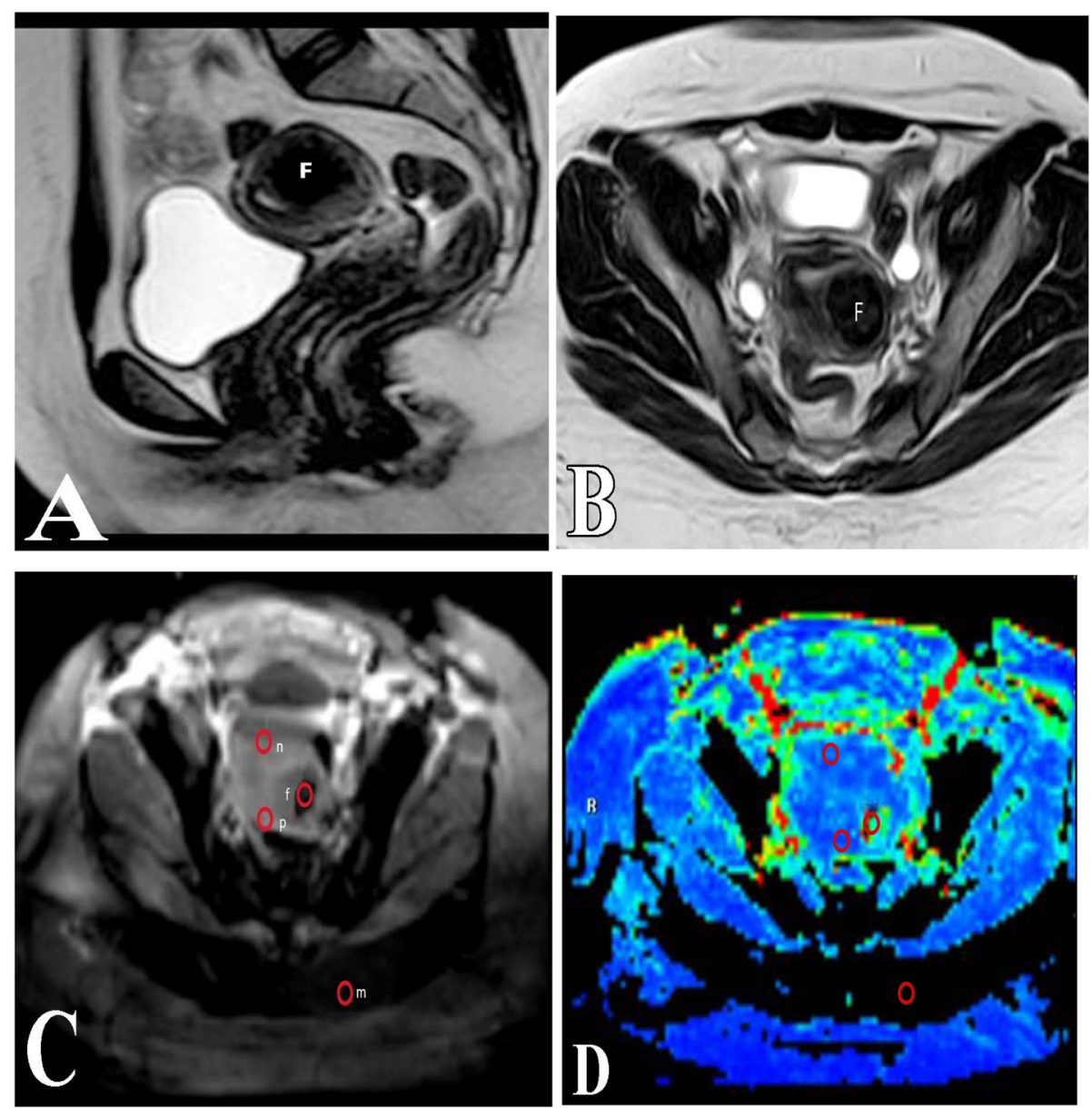

Fig. 3 Fertile female patient aged 44 years old. $\mathbf{a}$, b Sagittal and axial T2WI of the uterus showing posterior wall submucous fibroid [F] with low T2 SI measuring about $3 \times 3.5 \times 3 \mathrm{~cm}$ (ApxTrxHt). c ASL gray scale map and $\mathbf{d}$ ASL color map with the ROls placed in the anterior uterine wall (negative wall:n), posterior uterine wall (positive wall: $p$ ), fibroid (f), and the gluteus maximus muscle $(m)$. In this case, the perfusion of the positive wall was 486 , of the negative wall was 647 , and of the fibroid was 476 denoting that the perfusion was lower in the positive wall than the negative wall and the perfusion of the fibroid was less than both positive and negative uterine walls

includes a longer tagging bolus and thus higher signal to noise ratio (SNR) [24].

Quantitative assessment of myometrial perfusion was carried out in the study groups. In the control cases, there was no significant difference in the myometrial perfusion between the anterior and posterior uterine walls $(p$ value $=0.7$ ).

In patients with uterine fibroid, there was significant difference in the perfusion indices between positive and negative uterine walls (the fibroid positive side perfusion indices were significantly lower than the fibroid negative side) ( $p$ value $=0.04 *)$ and this difference was similarly noted in both fertile and infertile subgroups; this means that fibroids cause impairment of the perfusion in the ipsilateral uterine wall. This compromised blood flow towards the myometrium may be attributed to drainage of blood towards the fibroid.
On comparing the perfusion indices in the same uterine walls in the fertile fibroid subgroup with that of the infertile fibroid subgroup there was no significant difference in between denoting that the impairment of myometrial perfusion caused by the fibroid does not affect the fertility as a single factor.

After review of literature, there was lack of researches assessing myometrial perfusion changes in patients with uterine fibroids. It was postulated by $\mathrm{Ng}$ and $\mathrm{Ho}$ that the presence of fibroids results in significantly reduced uterine blood flow towards the endometrium and myometrium which agreed with our results [21].

On the other hand, our findings were in contrast to what was found by Takahashi et al. who stated that in patients harboring uterine fibroid, the ASL perfusion index of myometrium on the fibroid-positive side increased 4.9-fold compared with that of the fibroid- 

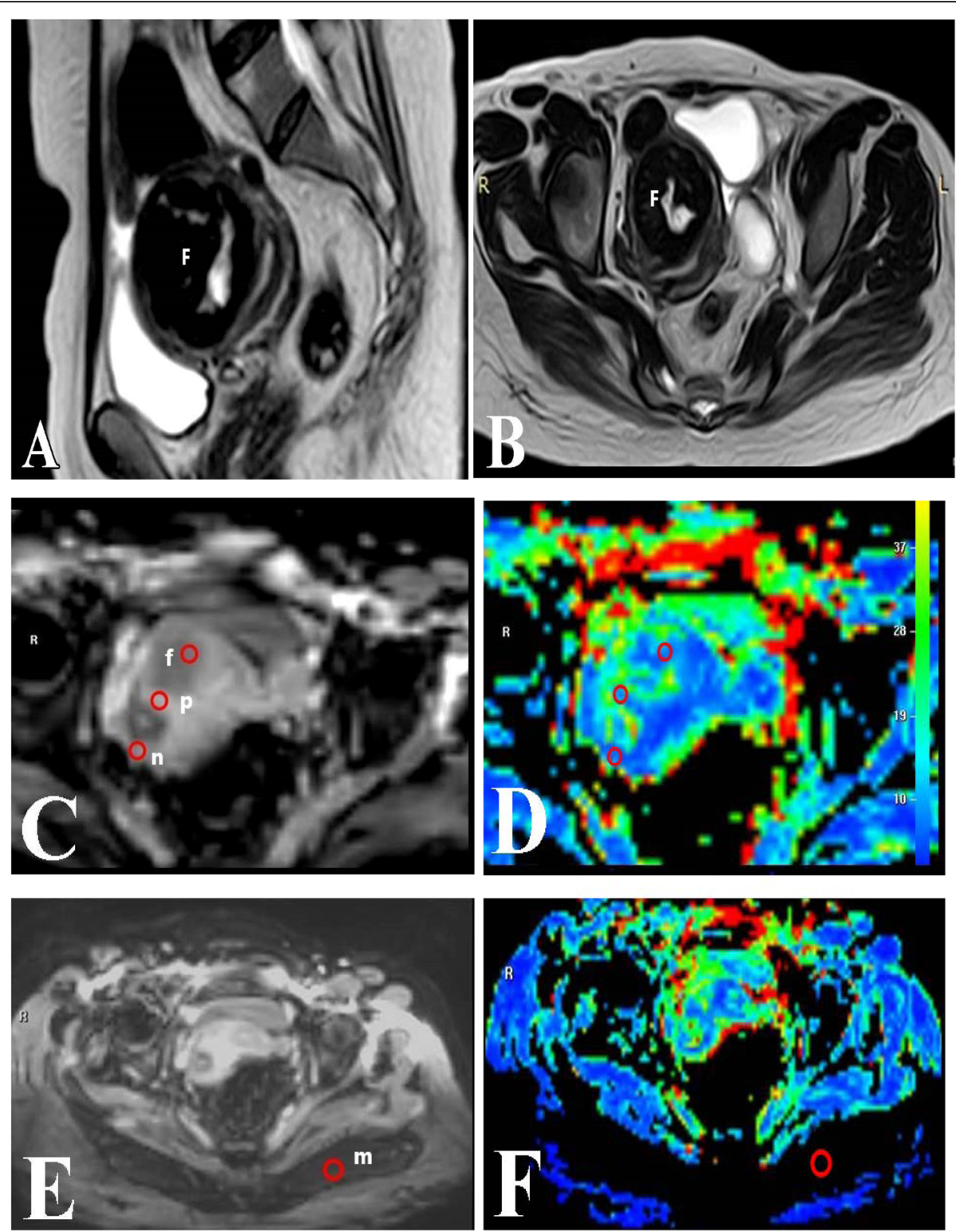

Fig. 4 Infertile female patient aged 41 years old. a, b Sagittal and axial T2Wl of the uterus showing anterior wall submucous fibroid [F] with low T2 SI and central areas of high T2 SI due to central necrosis measuring $6 \times 5 \times 5.5 \mathrm{~cm}$ (ApxTrxHt). $\mathbf{c}$, d ASL gray scale map and ASL color map with the ROls put at the anterior wall (positive wall; p), posterior wall (negative wall: $n$ ), and in the fibroid (f). e, $\mathbf{f}$ ASL gray scale map and color map with the ROI put at the gluteus muscle (m). In this case, the perfusion of the positive wall was 725, the negative wall was 862 while in the fibroid was 670 denoting that the perfusion was lower in the positive wall than the negative wall while the perfusion of the fibroid was less than both positive and negative uterine walls

Table 1 Range of perfusion values and perfusion indices of the positive wall, negative wall, and control muscle perfusion in patients with fibroid

\begin{tabular}{lll}
\hline Positive wall perfusion (median-IQR) & $\mathbf{5 7 1}$ & $\mathbf{3 0 8 - 7 3 9}$ \\
Negative wall perfusion (median-IQR) & $\mathbf{7 8 3}$ & $\mathbf{4 1 2 - 8 7 7}$ \\
Control muscle perfusion (Mean \pm SD) & $\mathbf{1 4 8 . 4}$ & $\mathbf{\pm 7 6 . 9 1}$ \\
Positive wall perfusion index (median-IQR) & $\mathbf{4 2 0}$ & $\mathbf{1 6 2 - 5 9 8}$ \\
Negative wall perfusion index (median-IQR) & $\mathbf{6 4 2}$ & $\mathbf{2 6 2 - 7 3 4}$ \\
\hline
\end{tabular}

Data expressed as mean \pm SD, median, IQR

$S D$ standard deviation, IQR interquartile range
Table 2 Comparison between the perfusion indices in the positive and negative walls in the fibroid patients

\begin{tabular}{lllll}
\hline & & $\begin{array}{l}\text { Negative wall } \\
\text { perfusion index }\end{array}$ & $\begin{array}{l}\text { Positive wall } \\
\text { perfusion index }\end{array}$ & $p$ value \\
\hline Fibroid patients & Median & 642 & 420 & $0.04^{*}$ \\
& IQR & $262-734$ & $162-598$ &
\end{tabular}

Data expressed as median, $I Q R$ interquartile range. $p$ probability *Significance $<0.05$, test used: Mann-Whitney test 
Table 3 Perfusion indices in the positive and negative walls in the two subgroups of fibroid patients (fertile and infertile)

\begin{tabular}{lllllll}
\hline & Fertile & & & Infertile & $p$ \\
\cline { 2 - 3 } & Median & IQR & & Median & IQR & \\
\hline $\begin{array}{l}\text { Positive wall } \\
\text { perfusion index }\end{array}$ & 464 & $222-629$ & & 335 & $84-598$ & 0.5 \\
$\begin{array}{l}\text { Negative wall } \\
\text { perfusion index }\end{array}$ & 660 & $294-745$ & 462 & $232-734$ & 0.37 \\
\hline
\end{tabular}

Data expressed as median, IQR interquartile range. $p$ probability

*Significance $<0.05$, test used: Mann-Whitney test

negative side which may be due to smaller number of patients included in their study [15]. In their study using 3D power Doppler, Kamel et al. also found that intramural fibroids $>4 \mathrm{~cm}$ significantly increase endometrial vascularity in infertile patients scheduled for IVF [25].

In our study, we found that the perfusion of the fibroid was less than the positive and negative uterine walls, yet with no statistically significant difference ( $p$ value $=0.94$ and 0.06 , respectively).

Our results also agreed with Carranza-Mamane et al. as they found that the blood flow to uterine fibroids is less than that of the adjacent myometrium [26]. Goodwin and Spies stated that the center of the fibroid is relatively hypovascular [27].

Also, McLucas found that the arterial supply to myoma was less than that of normal myometrium, and a myoma may degenerate when it outgrows its blood supply [28]. DeSouza and Williams reported that the myometrium was better perfused than leiomyomas which was attributed to several factors such as collateral circulation and larger myometrial vessels than in leiomyomas [29]. Fleischer et al. stated that the fibroid is relatively hypovascular than adjacent myometrium, and its interior is supplied by small centripetal arteries that originate in a rich perifibroid arterial plexus [30].

The limitation of our study was small number of control cases and fibroid patients included in both subgroups (fertile, infertile).

\section{Conclusion}

Perfusion changes associated with uterine fibroids can be assessed non-invasively using ASL technique. Our study revealed association between the presence of the fibroid and decreased perfusion of the related myometrium, but this perfusion impairment had no statistically significant impact on fertility as a sole factor. Further studies on large number of fertile and infertile patients with uterine fibroids before and after treatment are needed.

\section{Abbreviations}

IVF: In vitro fertilization; ASL: Arterial spin labeling; US: Ultrasound; MRI: Magnetic resonance imaging; PCASL: Pseudo-continuous arterial spin labeling; DICOM: Digital imaging and communication in medicine;
DSC: Dynamic susceptibility contrast; CASL: Continuous arterial spin labeling; PASL: Pulsed arterial spin labeling; UAE: Uterine artery embolization

\section{Acknowledgements}

Not applicable.

\section{Authors' contributions}

MM designed the study, revised, and adjusted the manuscript. AF performed clinical evaluation and referral of cases. DR collected and interpreted the patient data. NT was a major contributor in writing the manuscript and corresponding author. All authors read and approved the final manuscript.

\section{Funding}

Not applicable

\section{Availability of data and materials}

The datasets used and/or analyzed during the current study are available from the corresponding author on reasonable request.

\section{Declarations}

\section{Ethics approval and consent to participate}

This study was approved by the institutional review board of Faculty of Medicine, Mansoura University, Egypt (code number: MS.18.05.137). Written informed consent to participate in the study was obtained from all patients.

\section{Consent for publication}

All patients included in this research gave written informed consent to publish the data contained within this study. If the patients were deceased, or unconscious when consent for publication was requested, written informed consent for the publication of this data was given by their legal guardians.

\section{Competing interests}

The authors declare that they have no competing interests.

\section{Author details}

${ }^{1}$ Diagnostic Radiology Department, Faculty of Medicine, Mansoura University, Algomhoria Street, Mansoura City 35516, Egypt. ${ }^{2}$ Obstetrics and Gynecology department, Faculty of Medicine, Mansoura University, Algomhoria Street, Mansoura City 35516, Egypt.

Received: 4 February 2021 Accepted: 21 April 2021

Published online: 06 May 2021

\section{References}

1. Purohit P, Vigneswaran K (2016) Fibroids and infertility. Current obstetrics and gynecology reports 5(2):81-88. https://doi.org/10.1007/s13 669-016-0162-2

2. Zepiridis LI, Grimbizis GF, Tarlatzis BC (2016) Infertility and uterine fibroids. Best Practice \& Research Clinical Obstetrics \& Gynaecology 34:66-73. https:// doi.org/10.1016/j.bpobgyn.2015.12.001

3. Khan A, Shehmar M, Gupta JK (2014) Uterine fibroids: current perspectives. International journal of women's health 6:95-114. https://doi.org/10.2147/ IJWH.S51083

4. Shoaieb AA, Fawzy MA, Abdel-Fattah M (2019) Socio-demographic and reproductive health profile among Egyptian women with uterine fibroid. Med J Cairo Univ 87:2369-2377

5. Stewart EA, Cookson CL, Gandolfo RA, Schulze-Rath R (2017) Epidemiology of uterine fibroids: a systematic review. BJOG 124(10):1501-1512. https://doi. org/10.1111/1471-0528.14640

6. Rackow BW, Taylor HS (2010) Submucosal uterine leiomyomas have a global effect on molecular determinants of endometrial receptivity. Fertility and sterility 93(6):2027-2034. https://doi.org/10.1016/j.fertnstert.2008.03.029

7. Guo XC, Segars JH (2012) The impact and management of fibroids for fertility: an evidence-based approach. Obstet Gynecol Clin North Am 39(4): 521-533. https://doi.org/10.1016/j.ogc.2012.09.005

8. Tal R, Segars JH (2014) The role of angiogenic factors in fibroid pathogenesis: potential implications for future therapy. Human reproduction update 20(2): 194-216. https://doi.org/10.1093/humupd/dmt042 
9. Pelage JP, Cazejust J, Pluot E, Dref OL, Laurent A, Spies JB, Chagnon S, Lacombe $P$ (2005) Uterine fibroid vascularization and clinical relevance to uterine fibroid embolization. Radiographics 25(suppl_1):99-117. https://doi. org/10.1148/rg.25si055510

10. Ferré JC, Bannier E, Raoult H, Mineur G, Carsin-Nicol B, Gauvrit JY (2013) Arterial spin labeling (ASL) perfusion: techniques and clinical use. Diagnostic and interventional imaging 94(12):1211-1223. https://doi.org/10.1016/j.diii.2 013.06 .010

11. Van Dalen JW, Mutsaerts HJ, Nederveen AJ, Vrenken H, Steenwijk MD, Caan MW et al (2016) White matter hyperintensity volume and cerebral perfusion in older individuals with hypertension using arterial spin-labeling. Am J Neuroradiol 37(10):1824-1830. https://doi.org/10.3174/ajnr.A4828

12. Abdel Razek AA, Talaat M, El-Serougy L, Abdelsalam M, Gaballa G (2019) Differentiating glioblastomas from solitary brain metastases using arterial spin labeling perfusion and diffusion tensor imaging derived metrics. World Neurosurg 127:e593-e598. https://doi.org/10.1016/j.wneu.2019.03.213

13. Li C, Li X, Liu H, Wang R, Niu G, Yang J et al (2020) Revealing the decrease of renal cortical perfusion in primary glomerular disease and renal aging by arterial spin labeling. Iran J Radiol 17:e96147

14. Telischak NA, Detre JA, Zaharchuk G (2015) Arterial spin labeling MRI: clinical applications in the brain. Journal of Magnetic Resonance Imaging 41(5): 1165-1180. https://doi.org/10.1002/jmri.24751

15. Takahashi N, Yoshino O, Hiraike O, Maeda E, Nakamura M, Hori M, Harada M, Koga K, Saito S, Fujii T, Osuga Y (2016) The assessment of myometrium perfusion in patients with uterine fibroid by arterial spin labeling MRI. Springer plus 5(1):1907-1913. https://doi.org/10.1186/s40064-016-3596-0

16. Kosaka N, Fujiwara $Y$, Kurokawa T, Matsuda T, Kanamoto M, Takei N, Takata K, Takahashi J, Yoshida Y, Kimura H (2018) Evaluation of retained products of conception using pulsed continuous arterial spin-labeling MRI: clinical feasibility and initial results. Magnetic Resonance Materials in Physics, Biology and Medicine 31(4):577-584. https://doi.org/10.1007/ s10334-018-0681-0

17. Abrao MS, Muzii L, Marana R (2013) Anatomical causes of female infertility and their management. International Journal of Gynecology \& Obstetrics 123:S18-S24. https://doi.org/10.1016/j.ijgo.2013.09.008

18. Jayakrishnan K, Menon V, Nambiar D (2013) Submucous fibroids and infertility: Effect of hysteroscopic myomectomy and factors influencing outcome. Journal of human reproductive sciences 6(1):35-39. https://doi. org/10.4103/0974-1208.112379

19. Khaund A, Lumsden M (2008) Impact of fibroids on reproductive function. Best Pract Res Clin Obstet Gynaecol 22(4):749-760. https://doi.org/10.1016/j. bpobgyn.2008.01.009

20. Sunkara SK, Khairy M, El-Toukhy T, Khalaf Y, Coomarasamy A (2009) The effect of intramural fibroids without uterine cavity involvement on the outcome of IVF treatment: a systematic review and meta-analysis. Hum Reprod 25:418-429

21. $\mathrm{Ng} \mathrm{EH}, \mathrm{Ho} P C$ (2002) Doppler ultrasound examination of uterine arteries on the day of oocyte retrieval in patients with uterine fibroids undergoing IVF. Hum Reprod 17(3):765-770. https://doi.org/10.1093/humrep/17.3.765

22. Aherne EA, Koktzoglou I, Lind BB, Edelman RR (2019) Dynamic quantitative nonenhanced magnetic resonance angiography of the abdominal aorta and lower extremities using cine fast interrupted steady-state in combination with arterial spin labeling: a feasibility study. Journal of Cardiovascular Magnetic Resonance 21(1):55-66. https://doi.org/10.1186/s12 968-019-0562-3

23. Shirozu N, Morioka T, Tokunaga S, Shimogawa T, Inoue D, Arihiro S, Sakata A, Mukae N, Haga S, lihara K (2020) Comparison of pseudocontinuous arterial spin labeling perfusion MR images and time-of-flight MR angiography in the detection of periictal hyperperfusion. eNeurological Sci 19:100233. https://doi.org/10.1016/j.ensci.2020.100233

24. Borogovac A, Asllani I (2012) Arterial spin labeling (ASL) fMRI: advantages, theoretical constrains and experimental challenges in neurosciences. Int J Biomed Imaging 2012:818456

25. Kamel A, El-Mazny A, Ramadan W, Abdelaziz S, Gad-Allah S, Saad H et al (2018) Effect of intramural fibroid on uterine and endometrial vascularity in infertile women scheduled for in-vitro fertilization. Arch Gynecol Obstet 297(2):539-545. https://doi.org/10.1007/s00404-017-4607-2

26. Carranza-Mamane B, Havelock J, Hemmings R, Cheung A, Sierra S, Case A et al (2015) The management of uterine fibroids in women with otherwise unexplained infertility. J Obstet Gynaecol Canada 37(3):277-285. https://doi. org/10.1016/S1701-2163(15)30318-2
27. Goodwin SC, Spies JB (2009) Uterine fibroid embolization. N Engl J Med 13: 690-697

28. McLucas B (2008) Diagnosis, imaging and anatomical classification of uterine fibroids. Best Practice \& Research Clinical Obstetrics \& Gynaecology 22(4):627-642. https://doi.org/10.1016/j.bpobgyn.2008.01.006

29. DeSouza N, Williams A (2002) Uterine arterial embolization for leiomyomas: perfusion and volume changes at MR imaging and relation to clinical outcome. Radiology 222(2):367-374. https://doi.org/1 0.1148 /radiol.2222010584

30. Fleischer R, Weston GC, Vollenhoven BJ, Rogers PAW (2008) Pathophysiology of fibroid disease: angiogenesis and regulation of smooth muscle proliferation. Best Practice \& Research Clinical Obstetrics \& Gynaecology 22(4):603-614. https://doi.org/10.1016/j.bpobgyn.2008.01.005

\section{Publisher's Note}

Springer Nature remains neutral with regard to jurisdictional claims in published maps and institutional affiliations.

\section{Submit your manuscript to a SpringerOpen ${ }^{\circ}$ journal and benefit from:}

- Convenient online submission

- Rigorous peer review

- Open access: articles freely available online

- High visibility within the field

- Retaining the copyright to your article

Submit your next manuscript at $>$ springeropen.com 